\title{
Specific and dynamic lignification at the cell-type level controls plant physiology and adaptability
}

\author{
Delphine Ménard ${ }^{1,2, \dagger}$, Leonard Blaschek ${ }^{1, \dagger}$, Konstantin Kriechbaum $^{3}$, Cheng Choo Lee ${ }^{4}$, Chuantao Zhu ${ }^{3}$, \\ Nuoendagula ${ }^{5}$, Zoltán Bacsik ${ }^{3}$, Lennart Bergström ${ }^{3}$, Aji Mathew $^{3}$, Shinya Kajita ${ }^{5}$, and Edouard Pesquet ${ }^{1,2, *}$ \\ ${ }^{1}$ Department of Ecology, Environment and Plant Sciences (DEEP), Stockholm University, 10691 Stockholm, Sweden \\ ${ }^{2}$ Umeå Plant Science Centre (UPSC), Department of Plant Physiology, Umeå University, 90187 Umeå, Sweden \\ ${ }^{3}$ Department of Materials and Environmental Chemistry (MMK), Stockholm University, 10691 Stockholm, Sweden \\ ${ }^{4}$ Umeå Core Facility for Electron Microscopy (UCEM), Umeå University, 90187 Umeå, Sweden \\ ${ }^{5}$ Graduate School of Bio-Applications and Systems Engineering, Tokyo University of Agriculture and Technology, Tokyo \\ 184-8588, Japan
}

*Address correspondence to edouard.pesquet@su.se † These authors contributed equally

0000-0003-3943-1476 (LBl), 0000-0002-3737-5303 (KK), 0000-0002-5702-0681 (LBe), 0000-0001-7187-6059 (SK), 0000-0002-6959-3284 (EP)

\begin{abstract}
Lignins, abundant phenolic cell wall polymers that accumulate in vascular tissue, were essential for plant terrestrialization as they enable sap conduction and mechanical support. Although lignification is currently understood as a random process, different cell types accumulate lignins with different compositions. The biological significance of these cellular differences is however still unknown. We performed single cell analyses to decipher the specific roles of different lignins and their residues on sap conduction and mechanical strengthening in plant xylem, using inducible pluripotent cell cultures and genetically modified whole plants. We show that specific lignins dynamically accumulate in each cell type and their morphotypes using distinct genetic programs, and that different lignin residues have non-redundant roles on plant biomechanical and hydraulic properties. Lignin is therefore a dynamic polymer changing composition to tailor the load bearing and sap conduction properties of each cells, in order for plants to adapt to developmental and environmental constraints.
\end{abstract}

Key words: Arabidopsis, poplar, inducible pluripotent stem cell cultures, cell wall, lignin, controlled lignification, biomechanics, vessel collapse, cell morphotypes, drought resistance, single-cell quantitative image analyses, irregular xylem, structural equation modelling

\section{Introduction}

Complex multicellular organisms require adjustable vascular systems to maintain tissue hydration and prevent embolism independently and irrespective of developmental and environmental constraints. Vertebrate animals have a closed vascular system that functions under a self-adjustable positive pressure caused by the heart muscles and modulation of blood conduit diameters. In contrast, plants have an open system under environmentally-controlled negative pressure with nonadjustable conduits of different diameters. These conduit cells, the tracheary elements (TEs), are part of a tissue called xylem that both provides the load-bearing skeleton and the sap conduction network. The dual role of TEs is enabled by the reinforcement of their primary cell walls (PCWs) with secondary cell walls (SCWs), and the subsequent removal of the intracellular content, except for the cell walls, by programmed cell death (Ménard et al. 2015; Derbyshire et al. 2015). As the plant grows, new TEs form, die and connect to older TEs to form a contiguous hollow conductive network that channels the sap throughout the plant (Ménard and Pesquet 2015). Because TEs have to undergo cell death to become functional, they have been long considered to have a static role in plant sap conduction. Yet, to adapt to developmental and environmental changes, the organisation of the continuously growing xylem dynamically changes. This affects not only the proportion and organisation of the different TE morphotypes - narrow protoxylem (PX) with annular or spiral patterns or wide metaxylem (MX) with reticulate or pitted patterns, but also the cell types surrounding TEs - unlignified xylem parenchyma (XP) and lignified xylary fibres (XF) (Fig. S1; Chaffey et al. 2002; Derbyshire et al. 2015). In the conductive networks formed by connected hollow TEs, the sap only ascends due to a negative pressure pull caused by the water potential gradients $(\Psi)$ along the soil/plant/atmosphere continuum; the sap water is eventually released in the air as vapour by the evapotranspiration of leaves. $\Psi$ along the continuum depends on differences in capillary, osmotic, mechanical, gravitational and vapour pressures, causing $\Psi$ in soil and air to fluctuate with environmental conditions (Fig. S1). In contrast, plants control their $\Psi$ using both stomatal movements to regulate leaf transpiration rates, and the intracellular osmolarity of XPs and XFs to alter osmotic pressure (Bentrup 2017; Holbrook et al. 1995; Pockman et al. 1995). Al- 

made available under aCC-BY 4.0 International license.
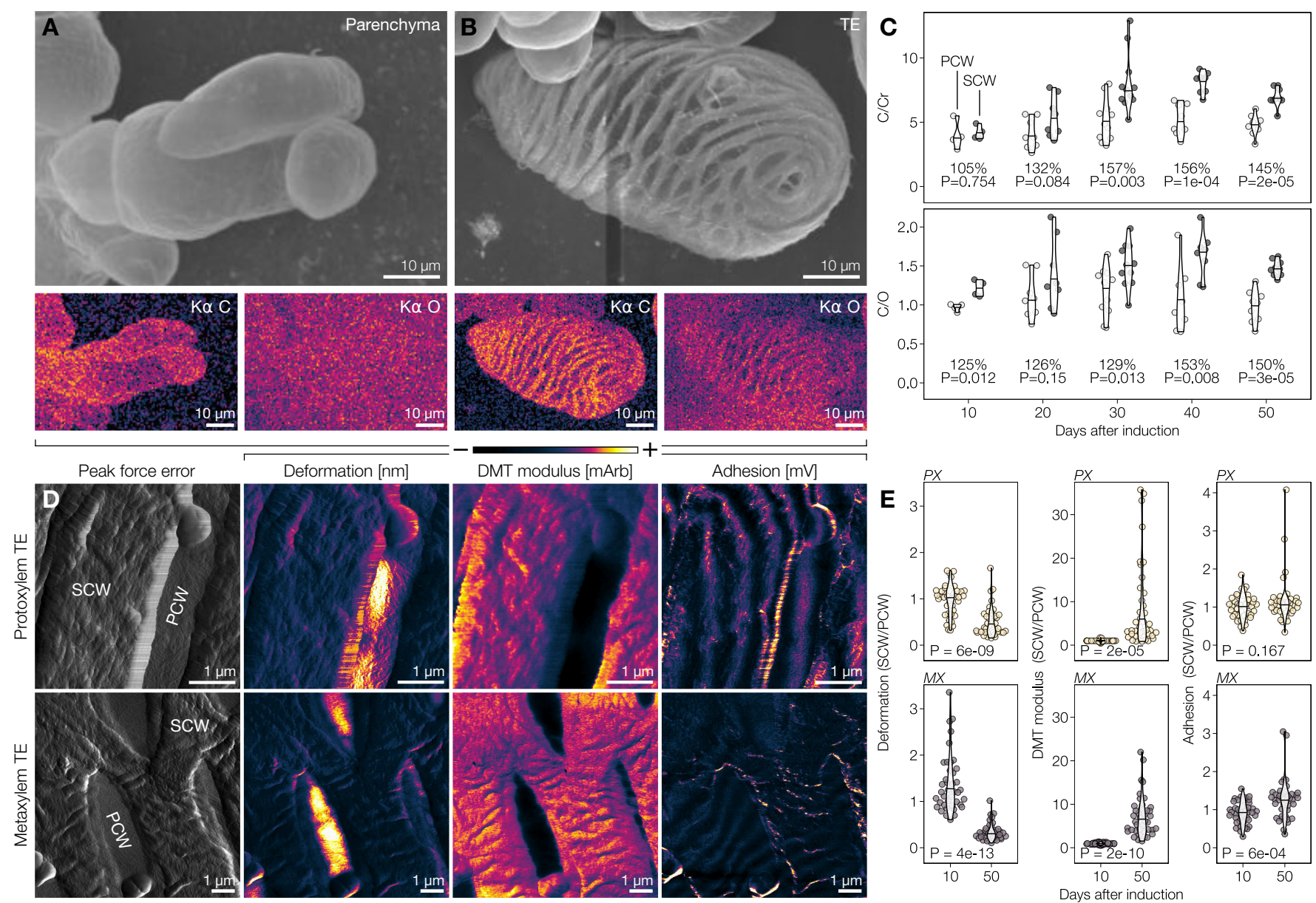

Figure 1 | Post-mortem lignification actively alters biomechanical properties of TE secondary cell walls (SCWs). A Scanning electron micrograph of isolated parenchyma cells, prepared using critical point drying (CPD), as well as its energy-dispersive X-ray spectroscopy (EDS) carbon (C) and oxygen (O) signals in color-coded intensity. B Scanning electron micrograph of an isolated tracheary element (TE) 30 days after induction, prepared by CPD, as well as color-coded intensity EDS $\mathbf{C}$ and $\mathbf{O}$ signals. $\mathbf{C}$ EDS ratios of $\mathbf{C}$ to $\mathbf{C r}(\mathbf{C} / \mathbf{C r})$ and $\mathbf{C}$ to $\mathbf{O}(\mathbf{C} / \mathbf{O})$ of $9 \mu \mathrm{m}^{2}$ (300 $\mathrm{nm}$ sided square) of the primary (PCW) and secondary cell wall (SCW) of isolated 10- to 50-day-old TEs. Note that SCWs gradually increase their $\mathbf{C} / \mathbf{O}$ ratio during post-mortem maturation. P-value of a two-tailed Welch's t-test as well as relative percentage change in elemental proportions between PCW and SCW are indicated; $n=4-11$ individual cells per time-point. D AFM peak force error as well as intensity color-coding of deformation, DMT modulus and adhesion of 50-day-old isolated protoxylem (PX) and metaxylem (MX) TEs. E SCW to PCW ratios of deformation, DMT modulus and adhesion of 10- and 50-day-old PX and MX TEs. P-value of a two-tailed Welch's t-test is indicated; $n=10$ measurements per cell wall type on 4 individual cells per time-point.

though the contribution of the mechanical pressure exerted by TE cell walls (the matric potential) is still unclear (Boyer 1967), we know TEs cannot withstand very large $\Psi$ changes, such as the ones due to extreme drought, and would collapse inwardly, disrupt sap transport resulting in embolism (Fig. S1; Brodribb and Holbrook 2005; Zhang et al. 2016; Coleman et al. 2008; Kitin et al. 2010; Voelker et al. 2011). However, the regulation of plant hydration by modulating structural features of TE morphotypes and xylem organisation remains poorly understood.

The xylem sap conduction properties, mechanical rigidity and toughness are determined by the accumulation in TEs of lignins, phenolic polymers with complex composition and structure (Barros et al. 2015; Pesquet et al. 2019). Unlike other cell wall polymers, lignin formation continues post-mortem in dead TEs by cooperating with neighbouring living XFs, XP and the xylem sap content which supply monomers (Pesquet et al. 2010; Pesquet et al. 2013; Derbyshire et al. 2015; Blaschek, Champagne, et al. 2020). This post-mortem lignification is catalyzed by highly stable and cell wall embedded oxidative enzymes, filling the gaps in between polysaccharidic cell wall polymers with lignins. The predominant lignin monomers are $\mathbf{C}_{6} \mathbf{C}_{3}$ phenylpropanoids varying in their $\mathbf{C}_{6}$ meta groups, such as monomethoxylated guaiacyl $(\mathbf{G})$ and dimethoxylated syringyl (S), and their $\mathbf{C}_{3}$ functions, such as alcohol $\left(\mathbf{X}_{\mathbf{C H O H}}\right)$ or aldehyde $\left(\mathbf{X}_{\mathbf{C H O}}\right)$ (Dixon and Barros 2019). Other lignin subunits with $\mathbf{C}_{\mathbf{6}}$ phenyl residue $(\mathbf{P})$ and $\mathbf{C}_{6} \mathbf{C}_{\mathbf{1}}$ benzaldehydes can also be incorporated in plant lignins. Due to the low spatial resolution, standard lignin analyses have led to consider lignin polymerisation as a random process only regulated by monomer supply (Barros et al. 2015). However, recent works challenged this model by showing that lignification is a genetically controlled process regulating the amounts, linkages and composition of lignin in each cell type and their different cell wall layers (Blaschek, Nuoendagula, et al. 2020; Blaschek, Champagne, et al. 2020; Yamamoto et al. 2020; Hiraide et al. 2021). Indeed, different TE morphotypes have been shown to contain lignins with different amounts and differently positioned $\mathbf{G}_{\mathbf{C H O}}$ (Blaschek, Champagne, et al. 2020; Yamamoto et al. 2020). Yet, the biological roles of lignin dynamics and diversity in each TE morphotype are still not understood. Herein, we investigated the biological roles of the xylem organisation, TE morphotypes 
bioRxiv preprint doi: https://doi.org/10.1101/2021.06.12.447240; this version posted June 14, 2021. The copyright holder for this preprint (which was not certified by peer review) is the author/funder, who has granted bioRxiv a license to display the preprint in perpetuity. It is made available under aCC-BY 4.0 International license.

and their specific lignins as well as their post-mortem lignification capacity. We used inducible plant pluripotent cell suspension cultures (iPSCs) and genetically engineered herbaceous and woody plants with modified lignins to show that each TE morphotype exhibits specific lignin amounts, composition and structures that change during post-mortem lignification. We demonstrated that the different lignin subunits are essential and non-redundant to fine-tune the biomechanical and hydraulic properties in each TE to sustain extreme $\Psi$ changes. Instead of being a "random" polymer, we demonstrated that lignin structure is specifically tailored during the maturation of each TE morphotypes to enable and dynamically adapt their conductive function in changing developmental and environmental conditions.
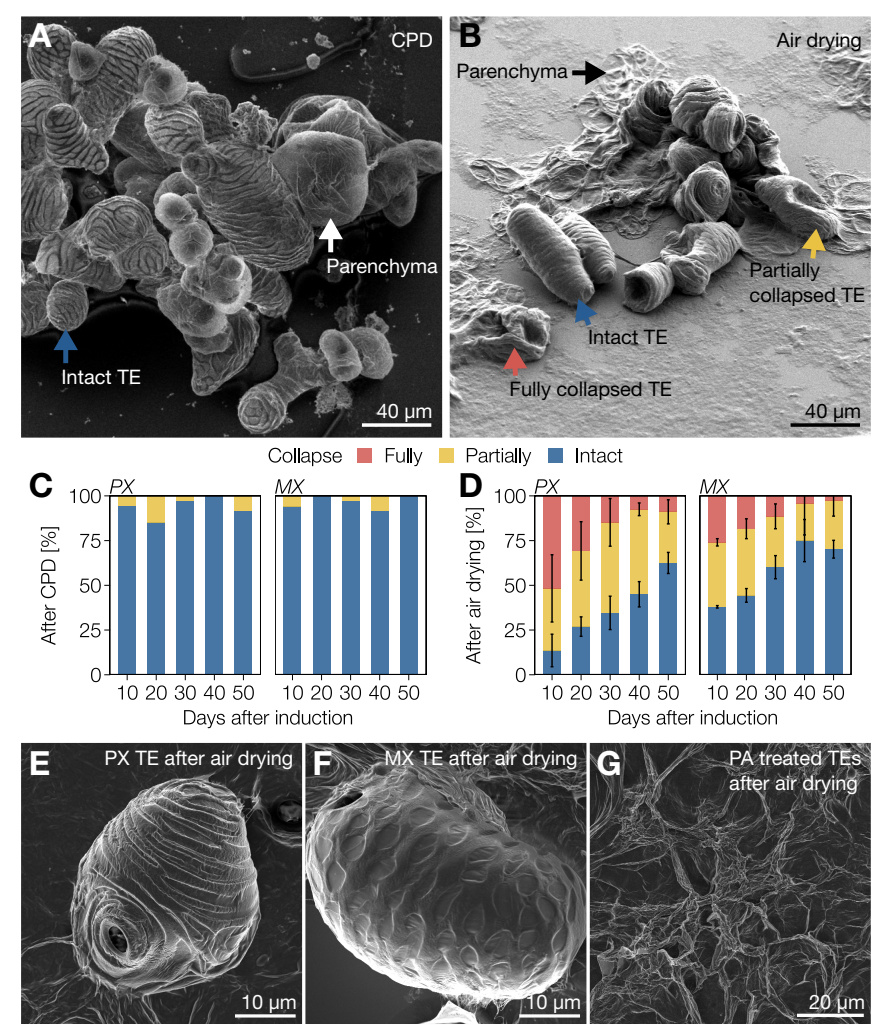

Figure 2 | Gradual post-mortem lignification enables all TE morphotypes to resist extreme $\Psi$ differentials. A Scanning electron micrograph of 30-day-old isolated TEs and parenchyma cells produced from iPSCs and prepared using critical point drying (CPD). Note that both TEs and parenchyma are intact as indicated by blue and white arrows respectively. B Scanning electron micrograph of 30-day-old isolated TEs and parenchyma cells produced from iPSCs and prepared using air drying. Note that parenchyma cells (black arrow) are completely flattened whereas TEs were either fully collapsed (red arrow), partially collapsed (yellow arrow) or intact (blue arrow). C Relative proportion of 10- to 50-day-old TEs from iPSCs that were fully collapsed, partially collapsed, or intact after CPD; $n=7-50$ individual cells per cell type and time-point. D Relative proportion of 10- to 50-day-old TEs from iPSCs that were fully collapsed, partially collapsed, or intact after air drying. Error bars represent \pm SD of 2 independent experiments; $n=$ 18-50 individual cells per cell type and time-point. E Scanning electron micrograph of a 30-day-old PX TE after air drying. F Scanning electron micrograph of a 30-day-old MX TE after air drying. G Scanning electron micrograph of 30-day-old unlignified TEs after air drying.

\section{Results}

Post-mortem lignification enables isolated TE morphotypes to resist extreme negative pressure. To define the role of lignins in TEs capacity to withstand extreme negative pressure, iPSCs were hormonally induced to produce intact and isolated TEs (Ménard et al. 2017). IPSCs synchronously formed all TE morphotypes, which underwent cell death 5-7 days after induction, followed by post-mortem lignification (Pesquet et al. 2010; Pesquet et al. 2013; Derbyshire et al. 2015). We monitored these post-mortem changes in TEs at the nanoscale using scanning electron microscopy (SEM) coupled with energydispersive X-ray spectroscopy (EDS) by measuring elemental changes in cell wall composition (Fig. 1A, B). Ratios of carbon (C) to coating chromium (Cr) content showed gradual postmortem increases of $\mathbf{C}$-rich compounds only in SCWs, which plateaued by day 50 (Fig. 1C). Ratios of carbon (C) to oxygen $(\mathbf{O})$ content revealed that the compounds accumulating post-mortem in TE SCWs were lowly oxygenated as expected from lignin (9 C:3-5 $\mathbf{O}$ for lignin-units compared to $6 \mathbf{C}: 6 \mathbf{O}$ for cellulose-units; Fig. 1C). Altogether we showed that TE SCWs continue lignifying for more than 40 days after cell death.

The impact of post-mortem lignification on TEs was then tested using atomic force microscopy (AFM) on 5-20 $\mu \mathrm{m}^{2}$ areas of isolated 10- and 50-day-old PX and MX TEs (Fig. 1D). AFM analysis showed that post-mortem lignification had no impact on PCW or on SCW surface adhesion but altered the biomechanical properties of SCW for each TE morphotype by significantly increasing stiffness and decreasing deformability (Fig. 1E). The role of these biomechanical changes in TE SCWs due to post-mortem lignification was evaluated in response to extreme $\Psi$ changes by exposing isolated 10- and 50-day-old TEs to two different drying methods and then observing them using SEM. Critical-point drying (CPD), which minimizes $\Psi$ changes during the drying process, was compared to air drying, which involves extreme $\Psi$ changes. Parenchymatic cells showed no collapse after CPD but were completely flattened by air drying (Fig. 2A, B) whereas TEs were similarly unaffected by CPD but withstood air drying (Fig 2A, B). The proportion of TEs fully or partially collapsed after air drying decreased as post-mortem lignification progressed, with the majority of 50-day-old TEs remaining completely intact (Fig. 2C, D). Both PX and MX TEs (Fig. 2E, F) withstood collapse in air drying better as postmortem lignification progressed, although PX were consistently more sensitive than MX TEs (Fig. 2C, D). To ensure that lignins were the factor determining the observed increased resistance, lignification of TE SCWs was prevented with piperonylic acid (PA) treatment (Van de Wouwer et al. 2016; Decou et al. 2017); as a result, unlignified TEs completely collapsed with air drying (Fig. 2G). We thus demonstrated for the first time that post-mortem lignification of TEs is a unique dynamic maturation process made to biomechanically reinforce TEs against $\Psi$ differentials for optimal sap conduction.

Specific lignin concentration and composition set the resistance of each TE morphotype to negative pressure in herbaceous whole plants. We then investigated TE lignification and resistance to collapse in herbaceous whole plants using Arabidopsis thaliana. Three TE morphotypes are present in 8-week old stems of wild-type (WT) plants, identifiable by their distance to the cambium: protoxylem TEs (PX), primary metaxylem TEs (PMX), and secondary metaxylem TEs (SMX) (Fig. 3A). All TEs were surrounded by $\sim 35 \%$ of other TEs whereas the remaining neighbouring cell types varied in 
bioRxiv preprint doi: https://doi.org/10.1101/2021.06.12.447240; this version posted June 14, 2021. The copyright holder for this preprint (which was not certified by peer review) is the author/funder, who has granted bioRxiv a license to display the preprint in perpetuity. It is made available under aCC-BY 4.0 International license.

the relative proportion of XP and XF (Fig 3B and S2). PX and SMX had smaller lumen diameters compared to PMX (Fig. 3C and S2). MXs presented higher lignin levels than PX (Fig. 3D). All TEs exhibited similar $\mathbf{S} / \mathbf{G}$ residue proportions (Fig. 3E) but showed different $\mathbf{C}_{\mathbf{6}} \mathbf{C}_{\mathbf{1}}$ benzaldehyde proportions, higher in PX than in MXs (Fig. 3F). Relative coniferyl alcohol $\left(\mathbf{G}_{\mathbf{C H O H}}\right)$ levels were higher in the SMX than in PX or PMX, whereas relative terminal coniferaldehyde $\left(\mathbf{G}_{\mathbf{C H O}}\right)$ residues were present in similar amounts in all three morphotypes (Fig. 3G, H). Therefore each TE morphotype has not only specific dimensions and neighbouring cells but also specific lignin composition, amounts, structures and organisation.
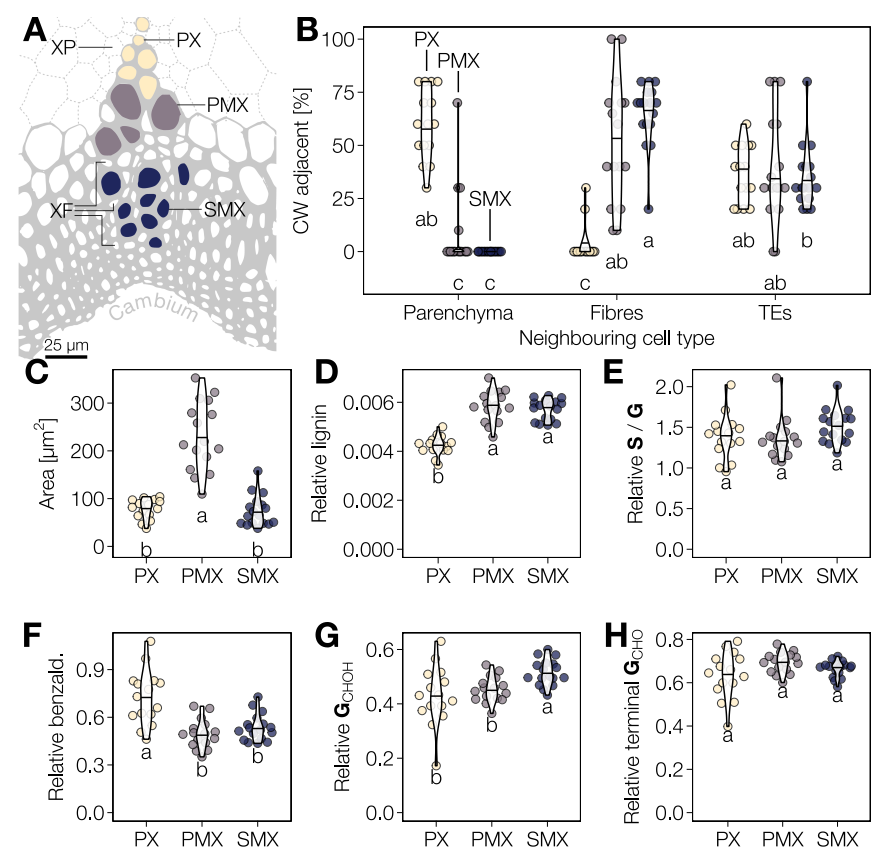

Figure 3 | Different TE morphotypes have specific morphological features and lignin biochemistry in herbaceous plants. A Scheme of the three TE types in the vascular bundles of Arabidopsis stems: protoxylem (PX) in yellow, primary metaxylem (PMX) in purple and secondary metaxylem (SMX) in blue. Along the developmental gradient from pith to cambium, different proportions of xylary fibres (XF) and xylem parenchyma (XP) surround each TE type. B Relative proportion of adjacent cell type for each TE morphotype. Note that the proportion of TEs neighboring other TEs remains constant independently of the TE considered. Letters indicate significant differences according to a Kruskal-Wallis test (Holm adjusted for multiple comparisons; $\alpha=$ 0.05). C Lumen area of each TE morphotype determined from cross sections. D-H Relative amounts of cell wall lignin (D), S/G compositional ratio $(\mathbf{E})$, relative benzaldehyde levels $(\mathbf{F}), \mathbf{G}_{\mathbf{C H O H}}$ levels $(\mathbf{G})$ and terminal $\mathbf{G}_{\mathbf{C H O}}$ levels $(\mathbf{H})$ for each TE morphotype determined by Raman microspectroscopy. Letters in panels $\mathrm{C}-\mathrm{H}$ indicate significant differences according to a Tukey-HSD test (per panel; $\alpha=0.05$ ); $n=15-17$ individual cells per vessel type across 3 individual stems.

TE collapse, also called irregular xylem (irx), has been previously observed in response to drought (Brodribb and Holbrook 2005; Zhang et al. 2016) but also when modifying lignification with genetic mutations (Turner and Sommerville 1997; Brown et al. 2005) or drugs (Amrhein et al. 1983; Smart and Amrhein 1985). We thus evaluated, for each different TE morphotype, the importance of lignin for the resistance to collapse using cross-sections of nine loss-of-function mutants altered in lignin concentration and/or composition. We measured area, perimeter, circularity, convexity, as well as lignin structure using in situ quantitative imaging (Blaschek, Nuoendagula, et al. 2020; Blaschek, Champagne, et al. 2020; Yamamoto et al. 2020). The perimeter or neighbouring cell types remained similar for all TE morphotypes between mutants (Fig. S2). TE circularity (indicating TE general deformation) and convexity (indicating TE inwards collapse), were however altered for specific TE morphotypes in distinct mutants. Plants mutated in CCR1 exhibited significantly reduced circularity and convexity in all TE morphotypes (Fig. 4A and S2). Plants mutated in both $4 C L 1$ and $4 C L 2$ showed TE collapse only in PX and PMX, mutants in CCOAOMT only affected PMX and mutants in both $C A D 4$ and $C A D 5$ were only compromised in PX (Fig. 4A and S2). Different TEs in each mutant exhibited significant differences in lignin structure (Fig. S3). These results revealed that specific changes in lignin, altering the $\mathbf{C}_{6}$ and $\mathbf{C}_{3}$ parts of lignin residues, differently control the biomechanical properties of each TE morphotype.

We computed structural equation models to link the morphological and biochemical changes for each TE morphotype. PX collapse was prevented by increases in lignin amount, $\mathbf{G}_{\mathbf{C H O H}}$ and terminal $\mathbf{G}_{\mathbf{C H O}}$ contents and TE perimeter (Fig. $4 B)$. Only $\mathbf{S}$ residue content escalated collapse, whereas $\mathbf{G}_{\mathbf{C H O}}$ position and the proportion of neighbouring TEs had no effect (Fig. 4B). In contrast, PMX collapse was prevented by increased lignin amount, total and terminal $\mathbf{G}_{\mathbf{C H O}}$ levels but was negatively affected by increases in $\mathbf{S}$ and neighbouring TEs (Fig. $4 \mathrm{C})$. This result complemented recent observations that showed collapse of PMX when genetically increasing their $\mathbf{S}$ content (Sakamoto et al. 2020). TE perimeter and $\mathbf{G}_{\mathbf{C H O H}}$ content did not affect PMX collapse (Fig. 4C). SMX collapse was prevented by increases in $\mathbf{G}_{\mathrm{CHOH}}$ but enhanced by increases in benzaldehydes (Fig. 4D). TE perimeter, number of neighbouring TEs, $\mathbf{S}$ and $\mathbf{G}_{\mathbf{C H O}}$ contents did not affect the collapse of SMX (Fig. $4 \mathrm{D})$. We also performed interaction analyses to determine the interdependence between morphological and biochemical features (Fig. S4). In the PX, the synergistic strengthening effects of $\mathbf{G}_{\mathbf{C H O H}}$ and $\mathbf{G}_{\mathbf{C H O}}$ against TE collapse were dependent on TE perimeter (Fig. S4). In the PMX, the effects of $\mathbf{G}_{\mathbf{C H O}}$ were similarly synergistic in preventing collapse with total lignin, but depended on vessel adjacency (Fig. S4). Overall, TE susceptibility to collapse was prevented for each TE morphotype by specific changes and interactions between cell/tissue morphology and lignin amount, composition $\left(\mathbf{S} / \mathbf{G}\right.$ and $\mathbf{G}_{\mathbf{C H O}} / \mathbf{G}_{\mathbf{C H O H}}$ compositional ratios) and structure ( $\mathbf{G}_{\mathbf{C H O}}$ terminal to total). Our results demonstrate that the different lignin residues have non-redundant roles and need to be specifically coordinated to determine the biomechanical properties of each TE morphotype.

TE resistance to negative pressure in woody plants depends on tissue organisation and post-mortem incorporation of specific subunits. We similarly evaluated TE lignification and resistance to collapse in woody whole plants of hybrid poplar by focusing in cross-sections of poplar stems on different TE types, primary (PV) and secondary xylem TE/vessels (SV), and different developmental states, young and old SVs defined within or beyond the $50 \%$ distance to the cambium (Fig. 5A). All TEs in WT plants had similar surrounding cell types but varied in the lumen area, which was smallest in young SVs (Fig. 5B, C). In situ analysis showed differences in lignin 
bioRxiv preprint doi: https://doi.org/10.1101/2021.06.12.447240; this version posted June 14, 2021. The copyright holder for this preprint (which was not certified by peer review) is the author/funder, who has granted bioRxiv a license to display the preprint in perpetuity. It is made available under aCC-BY 4.0 International license.

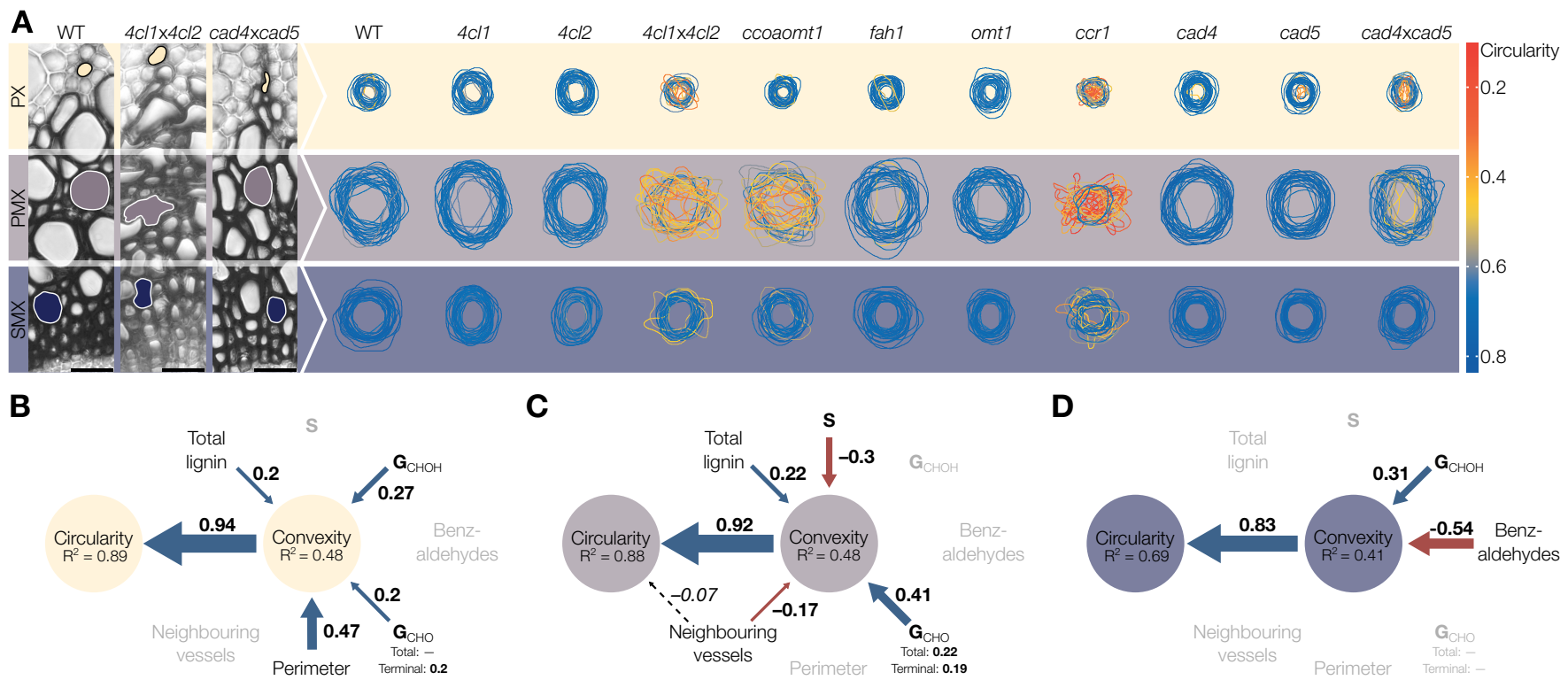

Figure 4 | Lignin structure differently alters the resistance of specific TE morphotypes in herbaceous plants. A Representation of 25 representative perimeters for each TE type in transverse cross-sections from stems of Arabidopsis thaliana loss-of-function mutants altered in lignin structure. TE outline colour indicates the circularity of each respective TE. B-D Structural equation models of the factors influencing TE convexity and circularity in the PX (B), PMX (C) and SMX (D) of Arabidopsis thaliana. Blue arrows and positive standardized coefficients indicate significant positive effects, red arrows and negative standardized coefficients indicate significant negative effects. Dashed arrows indicate predictors that were included and improved the model, but whose specific effects were not statistically significant. Greyed out variables did not improve the model and were excluded. See also supplementary figures S2-S4 and supplementary tables S1 and S2.

levels (lowest in PVs) and $\mathbf{S} / \mathbf{G}$ composition (highest in young SVs and gradually decreasing in old SVs and PVs) (Fig. 5D, E). Benzaldehyde and $\mathbf{G}_{\mathbf{C H O H}}$ levels (higher in PVs than SVs), and terminal $\mathbf{G}_{\mathbf{C H O}}$ levels (gradually increasing from young SVs to PVs) revealed changes between TE types as well as during their development (Fig. 5F-H). Complete analysis of TE maturation across wood sections showed gradual increases of

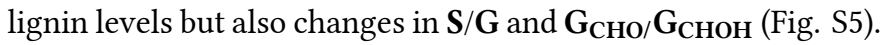
These results show that dynamic post-mortem lignification of TEs occurs in whole woody plants, and lead to different lignin structures.

To assess the link between lignin and TE collapse, we used two genotypes with reduced lignin amounts and composition by down-regulating $C 4 H$ and $C C R$. Lignin-reduced poplar plants had TEs with both significantly reduced circularity and convexity only in SVs (Fig. 5I and S6) but major changes in lignin composition and amounts were also observed for all TEs (Fig. S6). Structural equation models were computed to define the parameters affecting the collapse of each TE types as well as during SV post-mortem maturation. As PVs did not collapse, none of the measured parameters had any effect, thereby showing unique resilience of PVs (Fig. 5J). In contrast, old SVs collapse was prevented by increases of $\mathbf{G}_{\mathbf{C H O H}}$ and lignin levels but promoted by increases in terminal $\mathbf{G}_{\mathbf{C H O}}$ and $\mathbf{P}$ residues as well as increases in neighbouring TEs (Fig. 5K). The collapse of young SVs was prevented by increases of $\mathbf{G}_{\mathrm{CHOH}}$ but promoted by increases of $\mathbf{S}$, terminal $\mathbf{G}_{\mathbf{C H O}}$ and $\mathbf{P}$ residues, TE perimeter and neighbouring TEs (Fig. 5L). Similar to Arabidopsis, some of these effects were interdependent on each other. The effects of $\mathbf{P}$ and $\mathbf{G}_{\mathbf{C H O}}$ residues in old SVs were modulated by their adjacency to other vessels, while the negative effect of $\mathbf{G}_{\mathbf{C H O}}$ depended on high levels of $\mathbf{P}$ residues (Fig. S5). In young SVs, the effects of $\mathbf{S}, \mathbf{G}_{\mathbf{C H O}}$ and $\mathbf{P}$ values were similarly adjusted by each other and vessel perimeter/adjacency (Fig. S5).
Altogether, these results show that the non-redundant combinatory effects of lignin structure and cell neighbours on the biomechanical properties of specific TE types are dynamically modulated during their post-mortem maturation.

Lignin residues have non-redundant roles in controlling specific mechanical properties. To link the observed changes in lignin to whole plant mechanical properties, we performed flexure measurements using three point bending experiments on Arabidopsis plant stems (Fig. 6A and S7). We first evaluated the influence of turgor pressure and sap content on stem biomechanical properties by comparing flexure measurements of stem segments incubated in air, pure water or $1 \mathrm{M}$ sorbitol for several hours. Reducing water content in stems with sorbitol significantly reduced stem flexural strength and flexibility but not stiffness (Fig. 6B-C and S7). We then used two A. thaliana mutants to investigate how stem mechanical properties were affected by changes in lignin composition and concentration, specifically in the residues affecting TE collapse: the fah1 mutant, devoid of $\mathbf{S}$ and instead accumulating $\mathbf{G}_{\mathbf{C H O H}}$ (Meyer et al. 1998; Blaschek, Nuoendagula, et al. 2020; Yamamoto et al. 2020), and the cad4 $\times$ cad 5 mutant enriched in total and terminal $\mathbf{G}_{\mathbf{C H O}}$ (Blaschek, Champagne, et al. 2020; Sibout et al. 2005; Yamamoto et al. 2020). Biochemical analyses showed minor changes in lignin amounts, lower in fah1 and cad $4 \times$ cad 5 compared to WT plants, but major changes in $\mathbf{S} / \mathbf{G}$ and $\mathbf{G}_{\mathbf{C H O}} / \mathbf{G}_{\mathbf{C H O H}}$ as well as terminal/total $\mathbf{G}_{\mathbf{C H O}}$ (Fig. $6 \mathrm{D}$ and S7). Flexural strength and stiffness were significantly increased $\sim 2$-fold in the $\mathbf{S}$ devoid mutant, but significantly decreased $\sim 3$ fold in the $\mathbf{G}_{\mathbf{C H O}}$ enriched mutant, compared to the WT (Fig. $6 \mathrm{E}$ and S7). In contrast, flexibility was similar between fah1 and WT but significantly increased $\sim 3$-fold in cad4 $\times$ cad5 (Fig. $6 \mathrm{~F}$ ). Altogether, our results showed that $\mathbf{S} / \mathbf{G}$ controlled stem flex- 
bioRxiv preprint doi: https://doi.org/10.1101/2021.06.12.447240; this version posted June 14,2021 . The copyright holder for this preprint (which was not certified by peer review) is the author/funder, who has granted bioRxiv a license to display the preprint in perpetuity. It is made available under aCC-BY 4.0 International license.
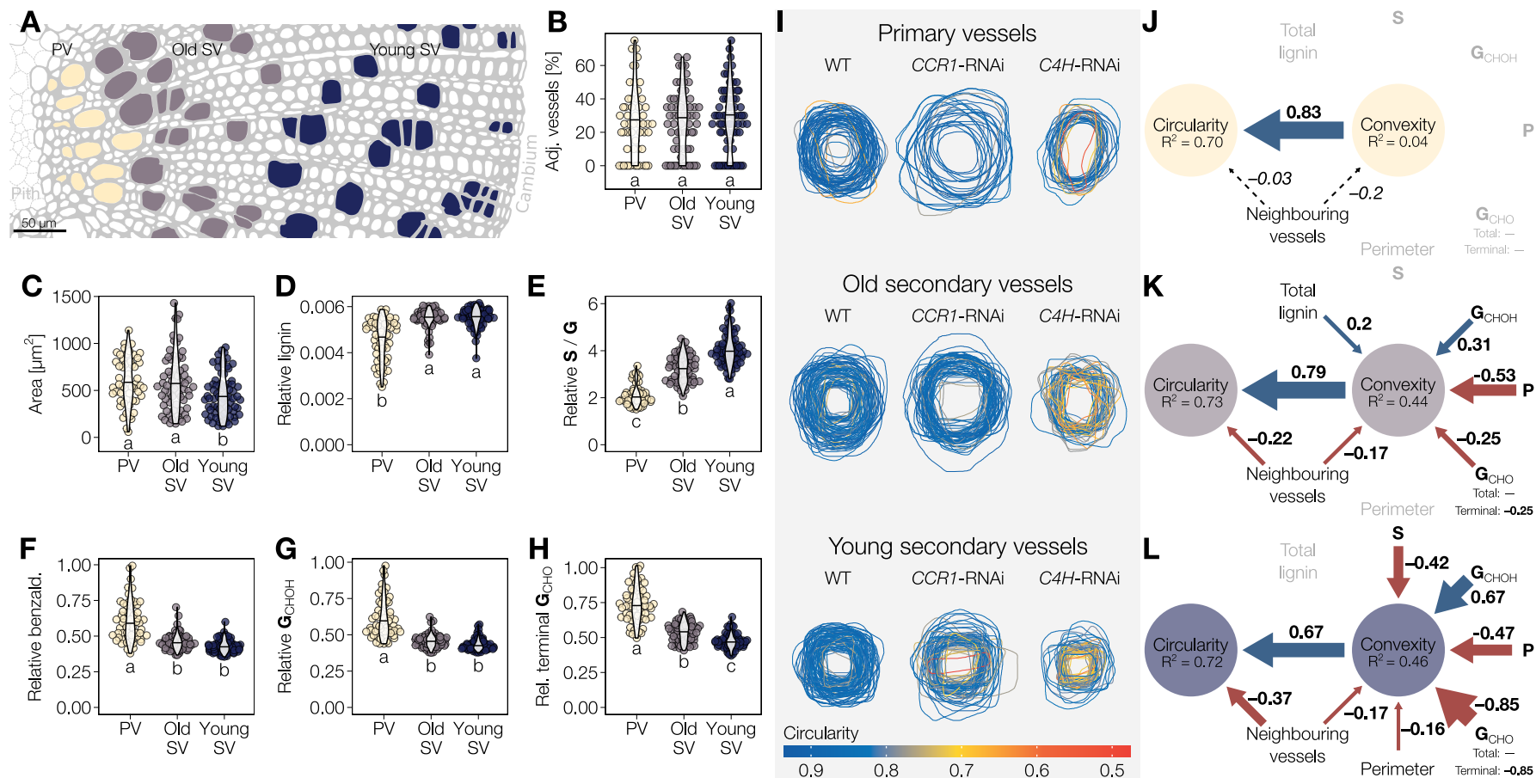

Figure 5 | Different TE morphotypes depend on specific post-mortem accumulated lignins for their resistance against collapse. A Scheme of the three TE types in the xylem of poplar stems, oriented on the pith-cambium axis: primary vessels (PV) in yellow, old secondary vessels (old SV) in purple and young secondary vessels (young SV) in blue. B Relative proportion of adjacent TEs to each TE types. Note that the proportion of TEs neighboring other TEs is independent of TE type and very similar to the proportions in A. thaliana. C Lumen area of each TE type determined from cross sections. D-H Relative amounts of cell wall lignin (D), $\mathbf{S} / \mathbf{G}$ compositional ratio $(\mathbf{E})$, relative benzaldehyde levels $(\mathbf{F}), \mathbf{G}_{\mathbf{C H O H}}$ levels (G) and terminal $\mathbf{G}_{\mathbf{C H O}}$ levels $(\mathbf{H})$ for each TE morphotype determined by Raman microspectroscopy. Letters in panels $\mathbf{B}-\mathbf{H}$ indicate significant differences according to a Tukey-HSD test (per panel; $\alpha=0.05$ ); $n=56-72$ individual cells from 5 individual plants per TE type. I Representation of TE perimeter for each TE type in transverse cross-sections from stems of Populus tremulaロtremuloides RNAi plants altering lignin biosynthesis. TE outline colour indicates the circularity of each respective TE. J-L Structural equation models of the factors influencing TE convexity and circularity in the PV (J), old SV (K) and young SV (L). Blue arrows and positive standardized coefficients indicate significant positive effects, red arrows and negative standardized coefficients indicate significant negative effects. Dashed arrows indicated predictors that were included and improved the model, but whose specific effects were not statistically significant. Greyed out variables did not improve the model and were excluded. See also supplementary figures S4-S6 and supplementary tables S1 and S2.

ural stiffness and strength, whereas $\mathbf{G}_{\mathrm{CHO}} / \mathbf{G}_{\mathrm{CHOH}}$ controlled stem flexibility, thereby providing mechanistic function behind the non-redundant roles of the different lignin residues.

\section{Increased TE flexibility due to lignin composition enables} plants to better resist drought. We then evaluated the role of TE flexibility due to $\mathbf{G}_{\mathbf{C H O}}$ residues on plant sap conduction capacity in response to normal watering or extreme $\Psi$ changes using simulated drought. Under normal condition, 4-5-weekold WT plant rosettes had evapotranspiration rates of $7.5 \mathrm{mg}$ water loss per min, which was significantly reduced by $\sim 25 \%$ under simulated drought with $10 \%$ and $20 \% \mathrm{PEG}_{6000}$ solution for 72h (Fig. 7A-C and S7). Leaf wilting and chlorosis were visible under simulated drought and accentuated by $\mathrm{PEG}_{6000}$ treatment (Fig. 7A, B). Recovery experiments by transferring plants to normal watering for $96 \mathrm{~h}$ showed that plants in $20 \% \mathrm{PEG}_{6000}$ did not recover whereas only one out of 8 plants in $10 \% \mathrm{PEG}_{6000}$ fully recovered (Fig. 7D). In the cad $4 \times c a d 5$ mutant, evapotranspiration rates gradually decreased with increasing $\mathrm{PEG}_{6000}$ levels (Fig. 7A-C and S7). However, the mutant plants showed less wilting and chlorosis than the WT, resembling the untreated plants (Fig. 7A, B). Recovery experiments to normal watering showed that $35-47 \%$ of cad $4 \times c a d 5$ plants fully recovered after both $10 \%$ and $20 \% \mathrm{PEG}_{6000}$ treatments (Fig. 7D). Overall our results showed that the increased flexibility conferred by $\mathbf{G}_{\mathbf{C H O}}$ residues to TEs enables plants to better resist the extreme $\Psi$ changes caused by drought. We therefore demonstrated that lignin structure directly controls the hydraulic properties of TEs to cope with environmental changes.

\section{Discussion}

Plants are unique in our biosphere in having an open vascular system that is driven by environmentally controlled water potential gradients $(\Psi)$. Despite this dependence on external conditions, plants possess an impressive capacity to survive and adapt in challenging habitats. Lignin in plant vascular tissues has until now been treated as a randomly assembled polymer with a structural role but no specific cellular or physiological function. Lignin residue diversity was however acquired several times convergently by different vascular plant genera during plant evolution (Weng et al. 2008). We recently questioned this "random" concept by showing that different xylem cell types, and their morphotypes, accumulated lignin $\mathbf{G}_{\mathbf{C H O}}$ residues using cell-specific genetic, cooperative and oxidative processes (Blaschek, Nuoendagula, et al. 2020; Blaschek, Champagne, et al. 2020; Yamamoto et al. 2020). We also showed that post-mortem lignification of TEs occurs in multiple plant species (Pesquet et al. 2010; Pesquet et al. 2013). Yet the physiological roles of TE post-mortem lignification and of specific lignin in each TE morphotype remained unclear. We herein demonstrated for the first time that each TE morphotype accumulates specific lignins (composition, concentration 
bioRxiv preprint doi: https://doi.org/10.1101/2021.06.12.447240; this version posted June 14, 2021. The copyright holder for this preprint (which was not certified by peer review) is the author/funder, who has granted bioRxiv a license to display the preprint in perpetuity. It is made available under aCC-BY 4.0 International license.

and structure) which are dynamically modified during its postmortem cell wall maturation. We showed that the different lignin residues had non-redundant effects on TE biomechanical properties. Lignin $\mathbf{S} / \mathbf{G}$ affected the stiffness and flexural strength whereas $\mathbf{G}_{\mathbf{C H O}} / \mathbf{G}_{\mathbf{C H O H}}$ modulated the flexibility, together with fine-tuning due to $\mathbf{G}_{\mathbf{C H O}}$ position, benzaldehydes and $\mathbf{P}$ residues as well as neighboring TE proportion and TE perimeter (Fig. 2-6 and S7). While increased $\mathbf{G}_{\mathbf{C H O}}$ had previously been suggested to compromise stem biochemical properties (Özparpucu et al. 2017; Özparpucu et al. 2018), we suggest that lignin composition finely regulates the trade-off between stiffness and flexibility.
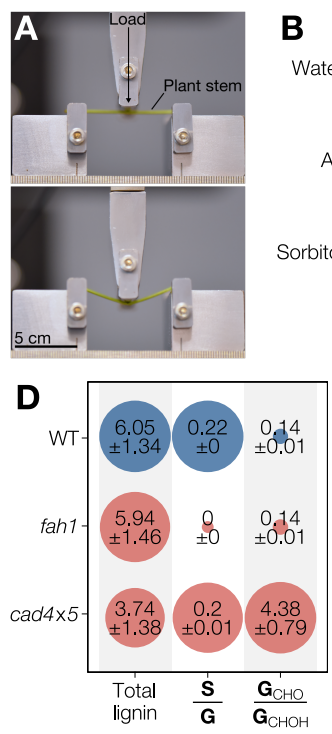

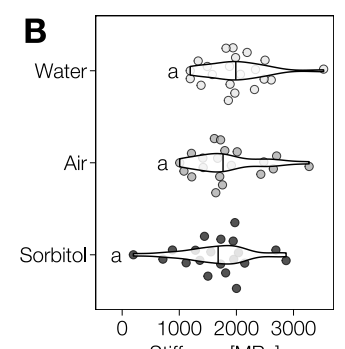

Stiffness [MPa]

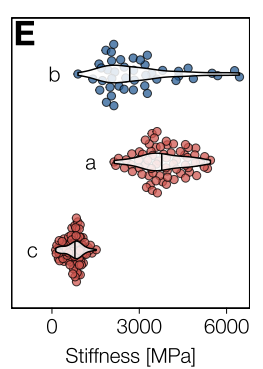

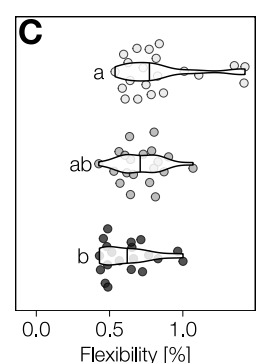

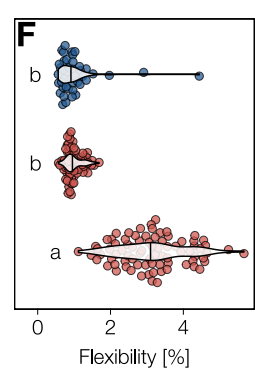

Figure 6 | Distinct lignin monomers control non-redundantly specific mechanical properties. A Arabidopsis thaliana stem segment undergoing three-point-bending. Note that flexural behavior is presented in movie S1. B, C The flexural stiffness (B) and sustained elastic deformation before irreversible breaking, i.e. flexibility, (C) of WT stem segments incubated in water, air, or sorbitol determined by three-pointbending; $n=5-8$ segments from 3 individual plants per condition. Letters indicate significant differences according to a Tukey-HSD test (per panel; $\alpha=0.05$ ). Note that turgor pressure contributes slightly to the extent of reversible elastic deformation, but not to its stiffness. D Total lignin content measured by thioglycolic acid derivatization, $\mathbf{S} / \mathbf{G}$ and $\mathbf{G}_{\mathrm{CHO}} / \mathbf{G}_{\mathrm{CHO}}$ ratios measured by pyrolysis-GC/MS for the three genotypes. Values are averages \pm SD of three independent replicates. $\mathbf{E}$, $\mathbf{F}$ The flexural stiffness (E) and sustained elastic deformation before irreversible breaking (F) of stem segments from WT, $\mathbf{S}$ depleted fah1 and $\mathbf{G}_{\mathbf{C H O}}$ over-accumulating cad $4 \times$ cad 5 mutant plants determined by three-point-bending; $n=10-24$ individual stems per genotype, cut into multiple segments. Letters indicate significant differences according to a Tukey-HSD test (per panel; $\alpha=0.05$ ). See also supplementary figure s7.

Our work moreover revises the current paradigm of plant xylem sap hydraulics, which considered TEs as static structures with no adaptive influence on plant sap conduction. We herein demonstrate that the mechanical properties of TEs due to specific lignins directly control their hydraulic properties. Altogether we show that post-mortem lignification of TEs is essential for vascular plants to dynamically adjust their vascular system to varying environmental conditions. The exact identity and function of the different cooperating cell types, the distance by which they can cooperate with TEs as well as the metabolites used and regulating molecular actors still need to be identified. Our study thereby completely revises the "random" lignification of plant cell to a genetically controlled process at the level of each cell morphotype to enable plants to thrive and dynamically adapt to changes in climate.
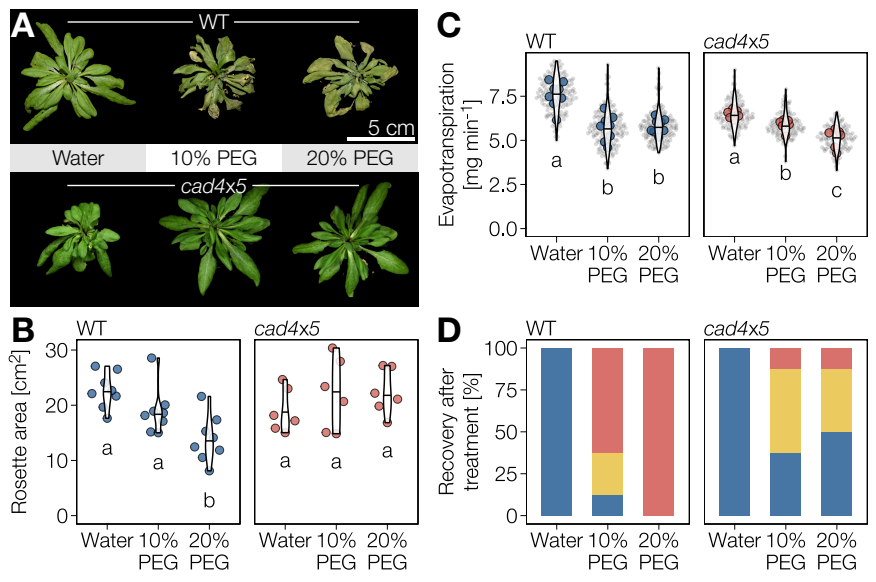

nead $\square$ Partly recovered $\square$ Recovered

Figure 7 | Coniferaldehyde induced flexibility of TE lignin improves plant resistance to, and recovery from, extreme $\Psi$ differentials. A Top view of 4- to 5-week-old $A$. thaliana WT and $\mathbf{G}_{\mathrm{CHO}}$ over-accumulating cad $4 \times c a d 5$ mutant plants after being irrigated with water, $10 \%$ PEG or $20 \%$ PEG for 3 days. B Top view rosette area after being irrigated with water, $10 \%$ PEG or $20 \%$ PEG for 3 days. Letters indicate significant differences according to a Tukey-HSD test (per panel; $\alpha=0.05$ ). C Evapotranspiration rates of WT and cad $4 \times c a d 5$ plants after being irrigated with water, $10 \%$ PEG or $20 \%$ PEG for 3 days. Small grey dots represent individual measurements, larger coloured dots represent the average per plant. Letters indicate significant differences according to a TukeyHSD test (per panel; $\alpha=0.05$ ). D Proportion of WT and cad $4 \times c a d 5$ plants that did not, partly or fully recover after being treated (with water, $10 \%$ PEG or $20 \%$ PEG for 3 days) by a 4 days recovery period in water-saturated soil. See also supplementary figure $\mathrm{S7}$.

\section{Materials \& methods}

Inducible pluripotent cell suspension cultures (iPSCs). Arabidopsis thaliana iPSCs were produced and induced to differentiate into isolated vessel elements as described by Pesquet et al. (2010) and Ménard et al. (2017). Cell suspensions were induced by adding hormones to $30 \mathrm{mg} \mathrm{ml}^{-1}$ of 9 days old cells (fresh weight) in 1x Murashige and Skoog (MS) medium (Duchefa, M0222.0025) at pH 6.0 with $10 \mu \mathrm{M}$ of morpholino-ethanesulfonate (Sigma-Aldrich, M8250) and $3 \%$ sucrose. Xylogenic induction was triggered by adding 3.2 $\mathrm{nM} \alpha$-naphthaleneacetic acid (Sigma Aldrich, N0640), $44.4 \mathrm{nM}$ 6-benzyl-aminopurine (Sigma Aldrich, B3408) and $4 \mu \mathrm{M} 24$ epibrassinolide (Sigma Aldrich, E1641). The inhibition of lignin monomer biosynthesis was performed by adding $12.5 \mu \mathrm{M}$ of piperonylic acid (Sigma-Aldrich, P49805) at the time of hormonal induction of TE differentiation in suspension cultures as described by Van de Wouwer et al. (2016) and Decou et al. (2017).

Plant material. Arabidopsis thaliana and hybrid poplar plants were grown in climacteric growth chambers under a $16 / 8 \mathrm{~h}$ long day light regime with $150 \mu \mathrm{mol} \mathrm{m}^{-2} \mathrm{~s}^{-1}$ illumination using (Aura T5 Eco Saver Long Life HO light tubes; AuraLight, Seweden) and $22^{\circ} \mathrm{C} / 18^{\circ} \mathrm{C}$ in $60 \%$ humidity. Arabidopsis thaliana mutants in the Columbia Col-0 background used included ccoaomt1 (SALK_151507; Kai et al. 2008), fah1 (EMS mutant; Meyer et al. 1998), omt1 (SALK_135290; Tohge et al. 2007), 4cl1- 
bioRxiv preprint doi: https://doi.org/10.1101/2021.06.12.447240; this version posted June 14, 2021. The copyright holder for this preprint (which was not certified by peer review) is the author/funder, who has granted bioRxiv a license to display the preprint in perpetuity. It is made available under aCC-BY 4.0 International license.

1 (SALK_142526; Van Acker et al. 2013), 4cl2-4 (SALK_110197; Li et al. 2015), 4cl1×4cl2, ccr1-3 (SALK_123-689; Mir Derikvand et al. 2008), cad4 (SAIL_1265_A06; Lee et al. 2017), cad5 (SAIL_776_B06;Lee et al. 2017) and cad4×cad5. Populus tremula $\times$ tremuloides hybrid poplars clone T89 were transformed as described by Nilsson et al. (1992) with RNA interference constructs targeting either CINNAMATE-4-HYDROXYLASE (Potri.013G157900; Bjurhager et al. 2010) or CINNAMOYL-COA REDUCTASE (Potri.003G181400) selected for best reduced gene expression (Escamez et al. 2017). Transgenic plants were grown in sterile magenta boxes on $0.5 \mathrm{x}$ MS medium jellified with $0.4 \%$ phytagel (Sigma, P8169). The plants were micro-propagated every 3-4 months by transplanting apical stem segment onto fresh medium.

Atomic Force Microscopy (AFM). AFM imaging was performed on cell samples air dried for less than 1 hour using a Dimension Icon AFM (Bruker, Nanoscope controller, Santa Barbara, CA, USA). The measurement was conducted under Peak-Force QNM mode in air condition by using the probe TESPA-V2 (Bruker). The force set-point was $0.15 \mathrm{~V}$. The height, peak-force error, DMT (Derjaguin-Muller-Toporov) modulus, adhesion, and deformation images were recorded after calibrating the probes on Mica. The images were processed by NanoScope Analysis 1.5 software (Bruker) and quantification performed using ImageJ distribution Fiji (Schindelin et al. 2012).

Scanning electron microscopy (SEM) coupled with Energy-dispersive X-ray spectroscopy (EDS). Cell samples for electron imaging and chemicals analysis were dispersed and sedimented on glass coverslips, then either (i) dehydrated in a series of graded ethanol and critical point dried (CPD) using a Leica EM CPD300 critical point dryer or (ii) submitted to air drying, and finally coated with $5 \mathrm{~nm}$ chromium using Quorum Technologies Q150T ES metal coater. The samples morphology was analyzed by field-emission scanning electron microscopy (SEM; Carl Zeiss Merlin) using an in-lens secondary electron detector at accelerating voltage of $4 \mathrm{kV}$ and probe current of $100 \mathrm{pA}$. Elemental composition measurements were performed using an energy-dispersive X-ray spectrometer (EDS; Oxford Instruments X-Max $80 \mathrm{~mm}^{2}$ ) at accelerating voltage of $10 \mathrm{kV}$ and probe current of $300 \mathrm{pA}$, where the elemental composition percentage is an average of multiple line and point analyses.

Histological preparation and analyses. Eight week old stem samples were cleared in $70 \%$ ethanol, rinsed in water and embedded in $10 \%$ agarose prior to sectioning to $50 \mu \mathrm{m}$ with a VT1000S vibratome (Leica, Sweden). Semi-quantitative Raman microspectroscopy was performed as described by Blaschek, Nuoendagula, et al. (2020) on the different vessel types using a confocal Raman microscope (RAMANplus, Nanophoton, Japan and LabRAM HR 800, Horiba, France) with a $532 \mathrm{~nm}$ laser. Averaged spectra were obtained from three to seven cell walls per TE morphotype and plant, in one to three plants per genotype for Arabidopsis and from 17 to 71 cell walls per TE morphotype and plant, in two to six plants for poplar. Quantitative Wiesner test was performed as described by Blaschek, Champagne, et al. (2020) using an Olympus BX60 brightfield microscope equipped with an Olympus UPFLN 40X objective (NA 0.75), an
Olympus XC30 CCD colour camera. TE morphological features (distance from cambium, lumen area, perimeter, circularity, neighbouring cell types) were measured from microscopy images using the ImageJ distribution Fiji (Schindelin et al. 2012). TE circularity was determined as $4 \pi\left(\right.$ area $/$ perimeter $\left.^{2}\right)$, and TE convexity as area/area of convex hull. Fiji macros are available at https://github.com/leonardblaschek/fiji.

Three point flexural test. The stiffness and strength of stems were assessed using three-point flexural tests with an Instron 5966 universal testing machine (Instron, USA) equipped with a $100 \mathrm{~N}$ load cell in a humidity and temperature controlled room $\left(50 \% \mathrm{RH}\right.$ and $\left.23^{\circ} \mathrm{C}\right) .4-5 \mathrm{~cm}$ long stem segments from $25-35$ cm stems of 6-7 week-old plants were placed on two supporting pins that were separated at an average span-to-diameter

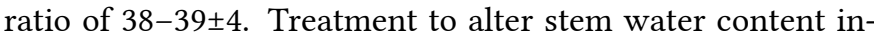
cluded incubation for several hours prior to bending in pure distilled water or 1M sorbitol (Sigma, S1876) solutions, all other measurements were performed in air. After manually lowering the loading pin until just in contact with the sample, the probe was lowered automatically at a constant displacement rate of $2 \mathrm{~mm} \mathrm{m^{-1 }}$ until a final displacement of $7 \mathrm{~mm}$. The flexural strength $\sigma_{\max }(\mathrm{MPa})$ was calculated as the maximum flexural stress using Eq. 1.

$$
\sigma_{\max }=\frac{8 F_{\max } L}{\pi d^{3}}
$$

In this equation, $F_{\max }(\mathrm{N})$ is the maximum force the specimen can withstand before kinking, $L(\mathrm{~mm})$ is the span length between the supporting pins, and $d(\mathrm{~mm})$ is the diameter of the circular cross-section of the specimen that was determined using optical microscopy imaging. The flexural stiffness $E$ (MPa) was calculated from the slope of the initial linear part of the flexural stress-strain curve using Eq. 2.

$$
E=\frac{4 F L^{3}}{3 \pi D d^{4}}
$$

In this equation, $D(\mathrm{~mm})$ is the maximum deflection of the centre of the stem. The flexibility of stems was defined as the strain at maximum stress, i.e. the amount of deformation a stem could endure before irreversibly breaking.

Evapotranspiration and simulated drought. Simulated drought treatments were made by watering plants with 0,10 or $20 \%$ polyethylene glycol (PEG) 6000 (Sigma-Aldrich, 8.07491) in tap water for $72 \mathrm{~h}$ in growing conditions $\left(150 \mu \mathrm{E}\right.$ light, $25^{\circ} \mathrm{C}$, $60 \%$ relative humidity). Evapotranspiration was measured using mass difference for 20 minutes on a LA-124i microbalance (VWR) directly connected to a computer and monitored using the i-Weight software (VWR). Plant recovery were made by placing plants directly in water for $72 \mathrm{~h}$. Light intensity, temperature and relative humidity were constantly monitored during the course of the measurements (Fig. S7). Images of the rosettes were acquired with a Nikon D750 camera equipped with a 50mm F1.4 DG HSM lens. Image segmentation and rosette area measurements were performed in Fiji (Schindelin et al. 2012). 
bioRxiv preprint doi: https://doi.org/10.1101/2021.06.12.447240; this version posted June 14,2021 . The copyright holder for this preprint (which was not certified by peer review) is the author/funder, who has granted bioRxiv a license to display the preprint in perpetuity. It is made available under aCC-BY 4.0 International license.

Lignin biochemical analysis. Lignin concentration in cell wall was determined after cell wall isolation according to Yamamoto et al. (2020) and the thioglycolic acid lignin derivatization as described by Suzuki et al. (2009) on purified cell walls. Absorbance was measured at $280 \mathrm{~nm}$ and calibrated using a regression curve obtained using different quantities of alkaline spruce lignin (Sigma Aldrich, 471003). Pyrolysis-GC/MS was used to measure $\mathbf{S} / \mathbf{G}$ and $\mathbf{G}_{\mathbf{C H O}} / \mathbf{G}_{\mathbf{C H O H}}$ according to Gerber et al. (2012) on $60 \mu \mathrm{g}( \pm 10 \mu \mathrm{g})$ of 8 -week-old stem samples. Thioacidolysis-GC/MS-FID was used to determine the terminal/total positional ratio of $\beta-O-4$ linked $\mathbf{G}_{\mathbf{C H O}}$ residues on 5 $\mathrm{mg}( \pm 1 \mathrm{mg})$ of isolated cell wall from 8-week-old stem samples as described by Yamamoto et al. (2020).

Data analyses and structural equation modelling. Data analysis and visualisation was performed in R (v4.0.4), using the tidyverse collection of packages (v1.3.0). The structural equation models were built using the piecewiseSEM package (v2.1.0; Lefcheck 2016). The included variables were measured for each individual vessel, except for the Wiesner test intensity in A. thaliana, for which the average per individual plant and vessel type was used. The multiple linear regression models comprising the structural equation models were selected using a bidirectional step-wise optimization approach, excluding interaction terms for clarity. Significantly contributing interaction terms were identified separately and visualized using the interactions R package (v1.1.1). Model fits and coefficients are summarized in table S1 and S2. R code used in this study is available at https://github.com/leonardblaschek/Rscripts/blob/master/irx_pub_figs.rmd.

\section{Acknowledgments}

We thank Louis Leboa, Charilaos Dimotakis and Drs. Elena Subbotina, Masanobu Yamamoto and Junko Takahashi-Schmidt for growing plants and providing lignin analysis in the different mutants. We thank Dr. Stefano Manzoni and Prof. Katharina Pawlowski for critical comments. We also thank the National Institute for Materials Science (NIMS) for access to Raman confocal microscope, the Albanova NanoLab for access to the AFM, the National Microscopy Infrastructure (NMI) for access to SEM-EDS. This work was supported by Gunnar Öquist fellowship from the Kempe foundation (to EP), Vetenskapsrådet (VR) research grants 2010-4620 and 2016-04727 (to EP), the Stiftelsen för Strategisk Forskning ValueTree (to EP), the Bolin Centre for Climate Research RA3 and RA4 "seed money" (to EP), and the Carl Trygger Foundation CTS 16:362/17:16/18:306 (to EP). Raman microspectroscopic analysis on plant cross sections was supported by the NIMS Molecule \& Material Synthesis Platform in the "Nanotechnology Platform Project" operated by the Ministry of Education, Culture, Sports, Science and Technology (MEXT), Japan. We also thank Bio4Energy (a strategic research environment appointed by the Swedish government), the UPSC Berzelii Centre for Forest Biotechnology, the Institute of Global Innovation Research (GIR) of Tokyo University of Agriculture and Technology (TUAT), and the Departments of Organic Chemistry, of Materials and Environmental Chemistry (MMK), of Ecology, Environment and Plant Sciences (DEEP) and the Bolin Centre for Climate Research of Stockholm University (SU).

\section{Author Contributions}

EP conceived the study. EP and DM designed the experiments. DM, LBl, KK, CZ, N, CCL, ZB and EP performed the experiments. LBl, KK, CCL, DM and EP analysed the data. LBe, AM, $\mathrm{ZB}$, SK and EP ensured financial support and scientific expertise. EP wrote the article. All co-authors revised the manuscript.

\section{References}

Amrhein, N., G. Frank, G. Lemm, and H. B. Luhmann. 1983. Inhibition of lignin formation by L-alpha-aminooxy-beta-phenylpropionic acid, an inhibitor of phenylalanine ammonia-lyase. European fournal of Cell Biology 29 (2): 139-144.

Barros, J., H. Serk, I. Granlund, and E. Pesquet. 2015. The cell biology of lignification in higher plants. Annals of Botany 115 (7): 10531074. https://doi.org/10.1093/aob/mcv046.

Bentrup, F.-W. 2017. Water ascent in trees and lianas: the cohesiontension theory revisited in the wake of Otto Renner. Protoplasma 254, no. 2 (2017): 627-633. https://doi.org/10.1007/s00709-0161009-4.

Bjurhager, I., A.-M. Olsson, B. Zhang, L. Gerber, M. Kumar, L. A. Berglund, I. Burgert, B. Sundberg, and L. Salmén. 2010. Ultrastructure and Mechanical Properties of Populus Wood with Reduced Lignin Content Caused by Transgenic Down-Regulation of Cinnamate 4-Hydroxylase. Biomacromolecules 11, no. 9 (2010): 23592365. https://doi.org/10.1021/bm100487e.

Blaschek, L., A. Champagne, C. Dimotakis, Nuoendagula, R. Decou, S. Hishiyama, S. Kratzer, S. Kajita, and E. Pesquet. 2020. Cellular and Genetic Regulation of Coniferaldehyde Incorporation in Lignin of Herbaceous and Woody Plants by Quantitative Wiesner Staining. Frontiers in Plant Science 11:109. https://doi.org/10. 3389/fpls.2020.00109.

Blaschek, L., Nuoendagula, Z. Bacsik, S. Kajita, and E. Pesquet. 2020. Determining the Genetic Regulation and Coordination of Lignification in Stem Tissues of Arabidopsis Using Semiquantitative Raman Microspectroscopy. ACS Sustainable Chemistry \& Engineering 8, no. 12 (2020): 4900-4909. https://doi.org/10.1021/ acssuschemeng.0c00194.

Boyer, J. S. 1967. Matric Potentials of Leaves. Plant Physiology 42 (2): 213-217. https://doi.org/10.1104/pp.42.2.213.

Brodribb, T. J., and N. M. Holbrook. 2005. Water Stress Deforms Tracheids Peripheral to the Leaf Vein of a Tropical Conifer. Plant Physiology 137, no. 3 (2005): 1139-1146. https://doi.org/10.1104/ pp.104.058156.

Brown, D. M., L. A. H. Zeef, J. Ellis, R. Goodacre, and S. R. Turner. 2005. Identification of Novel Genes in Arabidopsis Involved in Secondary Cell Wall Formation Using Expression Profiling and Reverse Genetics. The Plant Cell 17, no. 8 (2005): 2281-2295. https: //doi.org/10.1105/tpc.105.031542.

Chaffey, N., E. Cholewa, S. Regan, and B. Sundberg. 2002. Secondary xylem development in Arabidopsis: a model for wood formation. Physiologia Plantarum 114 (4): 594-600. https://doi.org/10.1034/j. 1399-3054.2002.1140413.x.

Coleman, H. D., A. L. Samuels, R. D. Guy, and S. D. Mansfield. 2008. Perturbed Lignification Impacts Tree Growth in Hybrid Poplar-A Function of Sink Strength, Vascular Integrity, and Photosynthetic Assimilation. Plant Physiology 148, no. 3 (2008): 1229-1237. https://doi.org/10.1104/pp.108.125500.

Decou, R., H. Serk, D. Ménard, and E. Pesquet. 2017. Analysis of Lignin Composition and Distribution Using Fluorescence Laser Confocal Microspectroscopy. In Methods in Molecular Biology, edited by M. de Lucas and J. P. Etchells, 1544:233-247. New York: Springer. https://doi.org/10.1007/978-1-4939-6722-3. 
bioRxiv preprint doi: https://doi.org/10.1101/2021.06.12.447240; this version posted June 14, 2021. The copyright holder for this preprint (which was not certified by peer review) is the author/funder, who has granted bioRxiv a license to display the preprint in perpetuity. It is made available under aCC-BY 4.0 International license.

Derbyshire, P., D. Ménard, P. Green, G. Saalbach, H. Buschmann, C. W. Lloyd, and E. Pesquet. 2015. Proteomic Analysis of Microtubule Interacting Proteins over the Course of Xylem Tracheary Element Formation in Arabidopsis. The Plant Cell 27 (October): 2709-2726. https://doi.org/10.1105/tpc.15.00314.

Dixon, R. A., and J. Barros. 2019. Lignin biosynthesis: old roads revisited and new roads explored. Open Biology 9 (12): 190215. https://doi.org/10.1098/rsob.190215.

Escamez, S., M. L. Gandla, M. Derba-Maceluch, S.-O. Lundqvist, E. J. Mellerowicz, L. J. Jönsson, and H. Tuominen. 2017. A collection of genetically engineered Populus trees reveals wood biomass traits that predict glucose yield from enzymatic hydrolysis. Scientific Reports 7, no. 1 (2017): 1-11. https://doi.org/10.1038/s41598017-16013-0.

Gerber, L., M. Eliasson, J. Trygg, T. Moritz, and B. Sundberg. 2012. Multivariate curve resolution provides a high-throughput data processing pipeline for pyrolysis-gas chromatography/mass spectrometry. Fournal of Analytical and Applied Pyrolysis 95:95-100. https://doi.org/10.1016/j.jaap.2012.01.011.

Hiraide, H., Y. Tobimatsu, A. Yoshinaga, P. Y. Lam, M. Kobayashi, Y. Matsushita, K. Fukushima, and K. Takabe. 2021. Localised laccase activity modulates distribution of lignin polymers in gymnosperm compression wood. New Phytologist n/a (n/a). https: //doi.org/10.1111/nph.17264.

Holbrook, N. M., M. J. Burns, and C. B. Field. 1995. Negative Xylem Pressures in Plants: A Test of the Balancing Pressure Technique. Science 270, no. 5239 (1995): 1193-1194. https://doi.org/10.1126/ science.270.5239.1193.

Kai, K., M. Mizutani, N. Kawamura, R. Yamamoto, M. Tamai, H. Yamaguchi, K. Sakata, and B. I. Shimizu. 2008. Scopoletin is biosynthesized via ortho-hydroxylation of feruloyl CoA by a 2-oxoglutarate-dependent dioxygenase in Arabidopsis thaliana. Plant fournal 55 (6): 989-999. https://doi.org/10.1111/j.1365313X.2008.03568.x.

Kitin, P., S. L. Voelker, F. C. Meinzer, H. Beeckman, S. H. Strauss, and B. Lachenbruch. 2010. Tyloses and Phenolic Deposits in Xylem Vessels Impede Water Transport in Low-Lignin Transgenic Poplars: A Study by Cryo-Fluorescence Microscopy. Plant Physiology 154, no. 2 (2010): 887-898. https://doi.org/10.1104/pp.110.156224.

Lee, S., H. Mo, J. I. Kim, and C. Chapple. 2017. Genetic engineering of Arabidopsis to overproduce disinapoyl esters, potential lignin modification molecules. Biotechnology for Biofuels 10 (1): 40. https://doi.org/10.1186/s13068-017-0725-0.

Lefcheck, J. S. 2016. piecewiseSEM: Piecewise structural equation modelling in R for ecology, evolution, and systematics. Methods in Ecology and Evolution 7 (5): 573-579. https://doi.org/10.1111/2041210X.12512.

Li, Y., J. I. Kim, L. Pysh, and C. Chapple. 2015. Four Isoforms of Arabidopsis 4-Coumarate:CoA Ligase Have Overlapping yet Distinct Roles in Phenylpropanoid Metabolism. Plant Physiology 169 (December): 2409-2421. https://doi.org/10.1104/pp.15.00838.

Ménard, D., S. Escamez, H. Tuominen, and E. Pesquet. 2015. Life Beyond Death: The Formation of Xylem Sap Conduits. In Plant Programmed Cell Death, 55-75. Springer. https://doi.org/10.1007/9783-319-21033-9_3.

Ménard, D., and E. Pesquet. 2015. Cellular interactions during tracheary elements formation and function. Current Opinion in Plant Biology 23:109-115. https://doi.org/10.1016/j.pbi.2014.12.001.

Ménard, D., H. Serk, R. Decou, and E. Pesquet. 2017. Establishment and Utilization of Habituated Cell Suspension Cultures for HormoneInducible Xylogenesis. In Methods in Molecular Biology, 1544:3757. https://doi.org/10.1007/978-1-4939-6722-3.

Meyer, K., A. M. Shirley, J. C. Cusumano, D. A. Bell-Lelong, and C. Chapple. 1998. Lignin monomer composition is determined by the expression of a cytochrome P450-dependent monooxygenase in Arabidopsis. Proceedings of the National Academy of Sciences 95 (12): 6619-6623. https://doi.org/10.1073/pnas.95.12.6619.

Mir Derikvand, M., J. B. Sierra, K. Ruel, B. Pollet, C.-T. Do, J. Thévenin, D. Buffard, L. Jouanin, and C. Lapierre. 2008. Redirection of the phenylpropanoid pathway to feruloyl malate in Arabidopsis mutants deficient for cinnamoyl-CoA reductase 1. Planta 227, no. 5 (2008): 943-956. https://doi.org/10.1007/s00425-007-0669-x.

Nilsson, O., T. Aldén, F. Sitbon, C. H. Anthony Little, V. Chalupa, G. Sandberg, and O. Olsson. 1992. Spatial pattern of cauliflower mosaic virus $35 \mathrm{~S}$ promoter-luciferase expression in transgenic hybrid aspen trees monitored by enzymatic assay and nondestructive imaging. Transgenic Research 1 (5): 209-220. https: //doi.org/10.1007/BF02524751.

Özparpucu, M., N. Gierlinger, I. Burgert, R. Van Acker, R. Vanholme, W. Boerjan, G. Pilate, A. Déjardin, and M. Rüggeberg. 2018. The effect of altered lignin composition on mechanical properties of CINNAMYL ALCOHOL DEHYDROGENASE (CAD) deficient poplars. Planta 247, no. 4 (2018): 887-897. https://doi.org/10.1007/s00425017-2828-z.

Özparpucu, M., M. Rüggeberg, N. Gierlinger, I. Cesarino, R. Vanholme, W. Boerjan, and I. Burgert. 2017. Unravelling the impact of lignin on cell wall mechanics: a comprehensive study on young poplar trees downregulated for CINNAMYL ALCOHOL DEHYDROGENASE (CAD). Plant fournal 91 (3): 480-490. https://doi.org/10. $1111 /$ tpj.13584.

Pesquet, E., A. V. Korolev, G. Calder, and C. W. Lloyd. 2010. The Microtubule-Associated Protein AtMAP70-5 Regulates Secondary Wall Patterning in Arabidopsis Wood Cells. Current Biology 20 (8): 744-749. https://doi.org/10.1016/j.cub.2010.02.057.

Pesquet, E., A. Wagner, and J. H. Grabber. 2019. Cell culture systems: invaluable tools to investigate lignin formation and cell wall properties. Current Opinion in Biotechnology 56:215-222. https: //doi.org/10.1016/j.copbio.2019.02.001.

Pesquet, E., B. Zhang, A. Gorzsás, T. Puhakainen, H. Serk, S. Escamez, O. Barbier, L. Gerber, C. Courtois-Moreau, E. Alatalo, L. Paulin, J. Kangasjarvi, B. Sundberg, D. Goffner, and H. Tuominen. 2013. Non-Cell-Autonomous Postmortem Lignification of Tracheary Elements in Zinnia elegans. The Plant Cell 25 (4): 1314-1328. https://doi.org/10.1105/tpc.113.110593.

Pockman, W. T., J. S. Sperry, and J. W. Oleary. 1995. Sustained and Significant Negative Water-Pressure in Xylem. Nature 378 (6558): 715-716. https://doi.org/10.1038/378715a0.

Sakamoto, S., N. Kamimura, Y. Tokue, M. T. Nakata, M. Yamamoto, S. Hu, E. Masai, N. Mitsuda, and S. Kajita. 2020. Identification of enzymatic genes with the potential to reduce biomass recalcitrance through lignin manipulation in Arabidopsis. Biotechnology for Biofuels 13, no. 1 (2020): 97. https://doi.org/10.1186/s13068-02001736-6.

Schindelin, J., I. Arganda-Carreras, E. Frise, V. Kaynig, M. Longair, T. Pietzsch, S. Preibisch, C. Rueden, S. Saalfeld, B. Schmid, J. Y. Tinevez, D. J. White, V. Hartenstein, K. Eliceiri, P. Tomancak, and A. Cardona. 2012. Fiji: An open-source platform for biologicalimage analysis. Nature Methods 9 (7): 676-682. https://doi.org/ 10.1038/nmeth.2019.

Sibout, R., A. Eudes, G. Mouille, B. Pollet, C. Lapierre, L. Jouanin, and A. Séguin. 2005. CINNAMYL ALCOHOL DEHYDROGENASE-C and $-D$ are the primary genes involved in lignin biosynthesis in the floral stem of Arabidopsis. The Plant cell 17, no. 7 (2005): 2059-76. https://doi.org/10.1105/tpc.105.030767.

Smart, C. C., and N. Amrhein. 1985. The Influence of Lignification on the Development of Vascular Tissue in Vigna radiata L. Protoplasma 124, no. 1 (1985): 87-95. https:// doi.org/10.1007/ BF01279727.

Suzuki, S., Y. Suzuki, N. Yamamoto, T. Hattori, M. Sakamoto, and T. Umezawa. 2009. High-throughput determination of thiogly- 
bioRxiv preprint doi: https://doi.org/10.1101/2021.06.12.447240; this version posted June 14, 2021. The copyright holder for this preprint (which was not certified by peer review) is the author/funder, who has granted bioRxiv a license to display the preprint in perpetuity. It is made available under aCC-BY 4.0 International license.

colic acid lignin from rice. Plant Biotechnology 26 (3): 337-340. https://doi.org/10.5511/plantbiotechnology.26.337.

Tohge, T., K. Yonekura-Sakakibara, R. Niida, A. Watanabe-Takahashi, and K. Saito. 2007. Phytochemical genomics in Arabidopsis thaliana: A case study for functional identification of flavonoid biosynthesis genes. Pure and Applied Chemistry 79 (4): 811-823. https://doi.org/10.1351/pac200779040811.

Turner, S. R., and C. R. Sommerville. 1997. Collapsed Xylem Phenotype of Arabidopsis Identifies Mutants Deficient in Cellulose Deposition in the Secondary Cell Wall. The Plant Cell 9 (5): 689-701. https://doi.org/10.1105/tpc.9.5.689.

Van Acker, R., R. Vanholme, V. Storme, J. C. Mortimer, P. Dupree, and W. Boerjan. 2013. Lignin biosynthesis perturbations affect secondary cell wall composition and saccharification yield in Arabidopsis thaliana. Biotechnology for Biofuels 6 (1): 46. https: //doi.org/10.1186/1754-6834-6-46.

Van de Wouwer, D., R. Vanholme, R. Decou, G. Goeminne, D. Audenaert, L. Nguyen, R. Höfer, E. Pesquet, B. Vanholme, and W. Boerjan. 2016. Chemical Genetics Uncovers Novel Inhibitors of Lignification, Including $p$-Iodobenzoic Acid Targeting CINNAMATE-
4-HYDROXYLASE. Plant Physiology 172 (1): 198-220. https:// doi.org/10.1104/pp.16.00430.

Voelker, S. L., B. Lachenbruch, F. C. Meinzer, P. Kitin, and S. H. Strauss. 2011. Transgenic poplars with reduced lignin show impaired xylem conductivity, growth efficiency and survival. Plant, Cell \& Environment 34 (4): 655-668. https://doi.org/10.1111/j.13653040.2010.02270.x.

Weng, J.-K., X. Li, J. Stout, and C. Chapple. 2008. Independent origins of syringyl lignin in vascular plants. Proceedings of the $\mathrm{Na}$ tional Academy of Sciences 105, no. 22 (2008): 7887-7892. https: //doi.org/10.1073/pnas.0801696105.

Yamamoto, M., L. Blaschek, E. Subbotina, S. Kajita, and E. Pesquet. 2020. Importance of Lignin Coniferaldehyde Residues for Plant Properties and Sustainable Uses. ChemSusChem 13 (17): 44004408. https://doi.org/10.1002/cssc.202001242.

Zhang, Y.-J., F. E. Rockwell, A. C. Graham, T. Alexander, and N. M. Holbrook. 2016. Reversible Leaf Xylem Collapse: A Potential "Circuit Breaker” against Cavitation. Plant Physiology 172 (4): 2261-2274. https://doi.org/10.1104/pp.16.01191. 